might show it to be 99 per cent pure, well within the commercial allowance, but it is still much inferior to a lot that would analyze 90 per cent Rhodamine and Io per cent dextrine and capable of dyeing a bright shade.

According to the ultimate uses of the dyes, tests are made in a manner that aims to duplicate, on a small scale, the actual application of the color. Dyeings on wool, cotton, and silk, the most common, are followed by paper pulp, lakes, leather, sugar, starch, etc. Colorimetric methods are more recent, but have many limitations.

If it were always possible to obtain identical conditions in the comparative dye test, the only source of error would be that of the individual's ability to read results accurately. However the dye test has shown that many influences, apparently insignificant, are capable of causing misleading results.

The water used in dyeing is a well-known factor, differences of over Io per cent being noted between filtered river water and distilled water. Dyes that are equal when tested by one observer may show a difference when tested by another on account of this condition. The presence of foreign material such as salt, Glauber salt, dextrine, or soluble starch may influence greatly the result of tests by two different laboratories. The salts generally act as precipitants and cause both superficial dyeing and lake formation in the dye bath, while the presence of the organic adulterants is like that of a protective colloid and results in slower dyeing, a less exhausted bath, and a greater penetration of the fiber. When the dye bath is finally exhausted, the appearance of the skein in both cases may be satisfactory to the raked eye, but the microscope will show that the one with the dye on the surface of the fiber has a false advantage.

The fibers themselves are not of a nature that would recommend them for exact scientific work. A wool fiber invariably dyes a very full and often bronzy shade near the tip, then becomes lighter toward the root, while the root end is often left practically unstained. The carding and spinning processes so mix the fibers that the naked eye does not notice these defects in a skein or piece of cloth, but they exist and the final result is modified accordingly. When the dye bath contains materials that influence the evenness of the individual fiber the dyeing as a whole shows the effect. These materials may be either actual impurities or placed there intentionally.

Silks are not uniform but are classed as hard-and soft-natured and accordingly dye superficially or uniformly.

Mordanted skeins may be the source of many differences between different observers. The tannin-antimony mordant on cotton is at times a true colloidal adsorption between cellulose and antimony tannate and at others a mechanical adhesion of the antimony compound on the surface of the fiber. The acidity of the dye bath removes and again deposits the final combination with the dye so that the most rigid maintenance of uniform conditions is necessary to obtain concordant results.

Lately a test of hematines by the method of non-oxidizing mordants was required in a hurry, and as no mordanted skeins were on hand they were prepared as usual and the dyeings followed at once. As the results were not satisfactory the test was repeated on the following day with mordanted skeins from the same lot: The second test showed almost double the amount of color of the first series, and the conclusion has been forced upon us that a chrome mordant on wool improves by ageing for 12 hours before use. Failure to observe this condition might result in discrepancies hard to explain.

The most satisfactory test of dyestuff strength is by the colorimeter, but such methods are only dependable when the two solutions are identical in composition and shade. Any variation in acidity, alkalinity, or tone of the color detract from accuracy. It is particularly noticeable now that the productions of different factories vary just enough to interfere with the use of the colorimeter, although it will be found most valuable in controlling the output of any plant.
A few words may be said on the subject of intermediates. It is vitally necessary that some authoritative body specify tests for the proper valuation of the common intermediates. The literature on the subjects is insufficient. Take the case of paraphenylene diamine. We can determine ash, nitrogen, melting and boiling point, solubility, and so on, but these are not a true indication of its suitability for dyestuff manufacture. The presence of isomeric bodies is the greatest fault and none of the ordinary tests are quantitative. It cannot be hoped that we will ever have a system of quantitative methods for aromatic compounds but some of the gaps may be filled. At times it is possible to convert an intermediate into a distinctive coloring matter and make a colorimetric comparison with a sample of the C. P. product and so far this has been the best method at hand.

Isolated cases like paranitraniline have given special methods, such as titration in boiling solution with sodium nitrate, using safranine as an indicator, but whenever there is a tendency to develop a strong color this method is valueless.

If we are now to make America the center of the dye industry it is incumbent upon us to provide the analyst with methods and so facilitate the commercial development along proper lines of control.

\section{ON THE QUANTITATIVE ANALYSIS OF DYESTUFFS}

By ALFRED H. HALLAND, of National Aniline and Chemical Company

The large majority of commercial dyestuffs contains besides the dyestuff proper a certain amount of moisture and a great variety of inert ingredients such as common salt, sulfate of soda, carbonate of soda, etc. While a certain amount of these bodies frequently are added in the process known as "Standardization," it is well known that it is practically impossible to isolate watersoluble dyestuffs without a minimum amount of salt, sulfate, and, to a lesser degree, sodium carbonate.

By the quantitative examination of a dyestuff I understand the determination of these various ingredients as well as of the coloring matter proper.

Before going into details I venture to state as my personal opinion that this line of work is being neglected in most dyestuff factories. When a manufacturing chemist delivers a quantity of dye to be "Standardized" he is too often satisfied if said quantity yields a fair amount of "Type." Am I much mistaken when I say that the chemist in many cases does not know what this "Type" really consists of? A quantitative analysis of each of his "Types" would show the chemist just what degree of perfection his manufacturing process has reached. It would either give him the satisfaction of knowing that his process was good or be an incentive to him to improve it. In the case of a great many complex dyestuffs, for example, certain polyazo dyestuffs, the actual yield of dyestuff from given quantities of intermediates is really quite poor. A quantitative analysis of the finished dyestuff, as well as of the intermediate azo bodies, should be instructive and should be carried out in all cases of bad yields. It wotld obviously only be necessary to do this work once for each individual "Type" as all future lots could be compared to the "Type" by the usual dyeing tests.

The quantitative determination of sulfur present as sulfonic acid groups, or of the degree of saturation of these with soda or potash, or of halogen, if such be present in the molecule, would form a valuable addition to the knowledge gained by a purely qualitative analysis of dyestuffs such as the chemist is occasionally called upon to make.

I now would like to review the methods which we have used in Buffalo with a fair degree of success. While I do not claim any scientific perfection or absolute accuracy for them, they have not been found seriously wanting.

\section{DETERMINATION OF MOISTURE}

Certain water-insoluble dyestuffs such as oil-solubla azo dyes, lake colors, bromo acid, etc., contain none, or very little moisture. 
The great mass of water-soluble dyestuffs contain moisture, partly loosely bound, and partly, and that I believe is the general rule, in the form of water of crystallization. It is interesting to observe the great tenacity with which even great quantities of water are retained by certain dyestuffs. This explains why the ordinary practice of drying organic compounds in a desiccator over sulfuric acid gives altogether too low figures for moisture when applied to dyestuffs. A sample of Wool Red $40 \mathrm{~F}$ lost in desiccator during 3 days 2 per cent in weight, while the same sample on drying to constant weight in an air oven at $125^{\circ}$ C. showed a loss of $\mathrm{r} 2$ per cent. This could be illustrated by a great many examples. For purposes of determining the moisture content it generally suffices to place the dyestuff in an air oven held at $125^{\circ} \mathrm{C}$., until constant weight is observed. The temperature of $125^{\circ} \mathrm{C}$, , or even higher, is generally tolerated by a dyestuff without any evidence of decomposition. It has been recommended to place the dyestuff for moisture determination in a tube through which a current of hydrogen or carbon dioxide is conducted while the tube is maintained at a constant temperature by being surrounded by vapors of a suitable liquid, for example, boiling toluol. These precautions are as a rule quite unnecessary except when dealing with easily oxidized dyestuffs.

\section{DETERMINATION OF SODIUM CHIORIDE}

When the dyestuff does not contain any halogen in the molecule or when it is not a hydrochloride, as in the case of basic colors, the salt determination is a simple matter. The general procedure is to mix the dyestuff intimately with from 5 to ro times its weight of C.P. anhydrous sodium carbonate and heat this mixture in an iron crucible gradually to a dull red heat turning the mass over occasionally with a steel spatula until complete charring or partial combustion has taken place. The crucible content is, after cooling, mixed intimately with pure potassium nitrate in the proper ratio to insure an easy flux and the mass placed in the crucible again, where it is cautiously heated until complete oxidation and fusion have taken place. The crucible content is then taken up with water, filtered, acidulated with nitric acid, and the sodium chloride determined in the usual manner with silver nitrate.

When halogen is present in the molecule it must be determined separately and the sodium chloride calculated by difference. In the case of basic dyes like Methylene Blue or Safranine, I believe a direct titration of the dyestuff by means of a standard solution of an acid dyestuff, for example, Naphthol Yellow according to Knecht or by titanous chloride according to Knecht and Hibbert would be advisable. The titanous chloride titration is altogether very satisfactory for a great many simple dyestufis, but fails in the case of more complex azo dyes.
DETERMINATION OF SULFATE OF SODA

This is not as simple as the salt determination and calls for greater ingenuity. Sometimes a direct precipitation in the acidulated solution of the dyestuff gives a fairly pure barium sulfate. As, however, a great many dyestuffs form hard soluble barium salts, the precipitated barium sulfate is often more or less colored. This can be corrected by washing the precipitate with warm ammonium carbonate whereby the color lake is decomposed into the ammonium salt of the dye which passes through the filter and barium carbonate which can be removed by dilute acid.

When the direct precipitation with barium chloride fails, it sometimes is a good plan to precipitate the dyestuff from its aqueous solution as thoroughly as possible with salt and determine the sulfate in the filtrate with eventual after-treatment with ammonium carbonate.

In some cases when the dyestuff cannot be "salted out," advantage can be taken of the fact that acid and basic dyestuff mutually precipitate one another. If, for example, the problem is to determine the amount of sulfate in Patent Blue or Acid Green a solution of a suitable basic color free from sulfates can be added to the solution of the acid color until a drop of the mixture placed on filter paper shows excess of the basic color. The condensation product is then filtered off and the barium sulfate precipitated in the filtrate. As a suitable basic color I prefer Chrysoidine, because it can be easily prepared free from sulfates.

By these various methods a determination of the sulfate of soda present in the dyestuff can be secured without a very high degree of accuracy.

\section{DETERMINATION OF SULFUR AND SODIUM OR POTASSIUM}

When the sulfate has been determined it is often of interest to determine the total sulfur present, including that residing in sulfonic acid groups. The fusion of $1 / 2 \mathrm{~g}$. or less of the dyestuff with soda and niter is generally more satisfactory than the classical heating in a sealed tube with nitric acid according to Carius.

The amount of sodium or potassium present in a dyestuff is easily found by moistening a small quantity of the sample in a porcelain or platinum dish, driving the sulfuric acid off by heating the crucible, and repeating this process until a perfectly white ash remains. This is then heated to a dull red heat and weighed as sodium sulfate.

After the chemist has made the series of quantitative determinations mentioned it should be possible by piecing them together to form a correct picture of the true composition of the dyestuff before him.

\section{CHEMICAL MARKETS OF SOUTH AMERICA}

By O. P. Hopkins, Washington, D. C.

\section{CHEMICAL TRADE OF CHILE, PERU, AND BOLIVIA}

Received August 27, 1918

The prosperity of Chile, Peru, and Bolivia depends primarily upon the output of minerals, and in this respect the group differs radically from Argentina, Brazil, and Uruguay, which were examined in connection with the trade in chemicals in the September number of ThIS JourNal. Sodium nitrate, copper, and tin are supplied by this group in enormous quantities and the value of these materials to the war industries of the belligerent countries is so great that the exporting countries have for the past two years been enjoying a prosperity that has transformed their whole economic life.
These countries are not, however, heavy importers of industrial chemicals. The market at present is confined largely to such articles as perfumery, medicines, paper, soap, and glass, and American manufacturers have succeeded in increasing their sales of these lines as the result of the shutting off of European supplies. The opportunity of the future lies in maintaining the advantage thus gained and developing the trade still further.

As in the previous review, there is a table showing the imports of each country, compiled from the original Spanish statistics, and more detailed tables showing the trade with the United States, based upon statistics published by the United States Bureau of Foreign and Domestic Commerce. 